\title{
WAVE RUN UP ON NATURAL BEACHES
}

\begin{abstract}
Andrew A. Mather ${ }^{1,2}$, Derek D. Stretch ${ }^{3}$ and Gerald G. Garland ${ }^{1}$
Wave run up is important for quantifying risks to infrastructure in the coastal zone. The performance of global wave run up models are assessed by applying them to two significant storms along the South African coastline in 2007 and 2008. The models produced mixed results and therefore the development of a new wave run up model was undertaken. This model uses the distance offshore to a point on the bathymetric profile, located approximately at the cut off depth, as a proxy for the underwater beach profile. This new wave run up model has been calibrated for open coastlines as well as large and small embayments. The new model outperforms most of the current wave run up models and gives a good first order approximation of wave run up on natural beaches.
\end{abstract}

Keywords: hazard zone, wave run up, natural beaches

\section{INTRODUCTION}

Wave run up is an important indicator of the risk zone associated with built structures and therefore the prediction of this is important in understanding the risks associated with the placement of infrastructure in this zone. Over the last three years, two significant events have occurred along the South African coastline causing extensive damage to beaches and infrastructure (Figure 1). In March 2007, a cut off low, trapped in a stationary position, created waves $\left(\mathrm{H}_{\mathrm{m} 0}=8.5 \mathrm{~m}\right.$ and $\mathrm{T}_{0}=16.6 \mathrm{sec}$, with $\mathrm{H}_{\mathrm{m} 0}>4 \mathrm{~m}$ for $39 \mathrm{hrs}$, estimated return period of $\left.50 \mathrm{yrs}\right)$ that impacted \pm 450 kilometers of shoreline along the KwaZulu-Natal coastline. In September 2008 a low-pressure system created waves $\left(\mathrm{H}_{\mathrm{m} 0}=10.3 \mathrm{~m}\right.$ and $\mathrm{T}_{0}=15.3 \mathrm{sec}$, with $\mathrm{H}_{\mathrm{m} 0}>6 \mathrm{~m}$ for $>40 \mathrm{hrs}$, estimated return period of $\left.25 \mathrm{yrs}\right)$ that impacted $\pm 1500 \mathrm{kms}$ of coastline from Cape Town to Port Elizabeth.

Despite much research work on empirical models development to determine wave run-up on artificial slopes, little research work on wave run-up on natural beaches has been undertaken. Previous wave run-up research on natural beaches has adopted one of two approaches. The first approach is where data covering a wide range of storm events is recorded at a single location. Typical of this approach has been the work of Holman (1986) who used data from the US Army research facility at Duck, USA. The data coverage was over a range of wave heights, $0.4 \mathrm{~m}$ to $4.0 \mathrm{~m}$, but was constrained to only a narrow band of beach slopes around 0.1 . The second approach is where data is gathered from several different geographical locations. An example of this approach has been the work of Nielsen and Hanslow (1991) who collected data from six beaches in New South Wales, Australia. The data coverage was for a range of wave heights from $0.53 \mathrm{~m}$ to $3.76 \mathrm{~m}\left(\mathrm{H}_{0 \mathrm{rms}}\right)$, wave periods from 6.4 to 11.5 seconds, and beach foreshore slopes in the range 0.026 to 0.189 .

\footnotetext{
${ }^{1}$ School of Environment Science, University of KwaZulu-Natal, Durban, KwaZulu-Natal, 4041, South Africa.

2 eThekwini Municipality, P. O. Box 680, Durban, KwaZulu-Natal, 4000, South Africa.

${ }^{3}$ Civil engineering Department, University of KwaZulu-Natal, Durban, KwaZulu-Natal, 4041, South Africa
} 


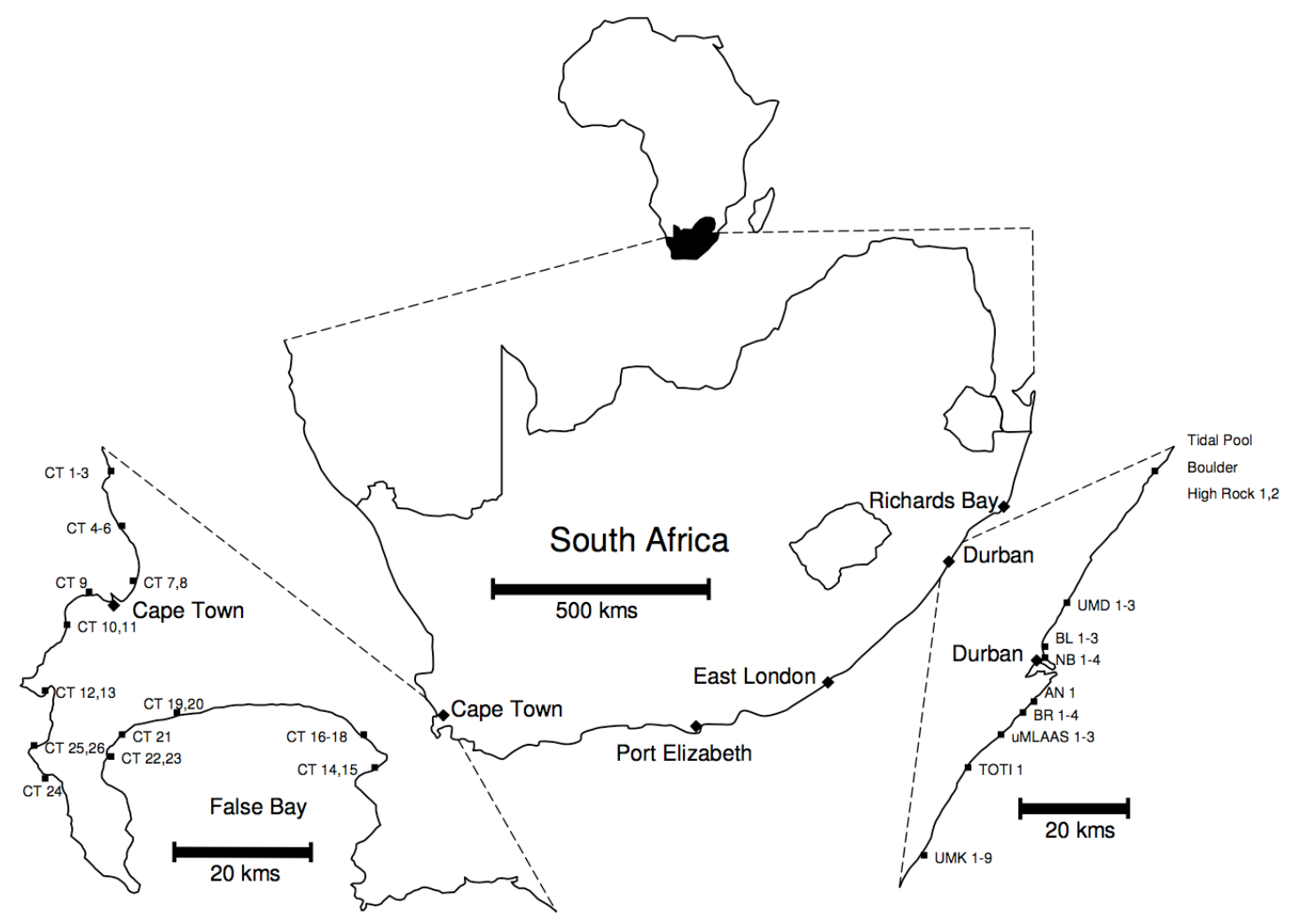

Figure 1: Location of wave run up recordings.

However there is a third possible approach. This is when data from a single storm event is collected from a large number of beaches. In this case the range of wave heights is fixed, but the beach parameters can vary considerably. This third approach was used for the present study.

\section{MATERIALS AND METHODS}

Shortly after each storm event, the debris line observable along the beaches were surveyed using municipal land surveyors at locations along the KZN and Cape coastline. These debris line levels have been observed to be similar to the $\mathrm{R}_{2 \%}$ wave run up heights (Nielsen, P. Pers. Comm. 2010). These wave run up levels where then determined as heights above the still water level (SWL) using the state of the tide during the storm event. The data was used to develop a new wave run up model based on the bathymetric profile. To test this proposed relationship, wave run-up heights along the KZN coastline were compared to the slope of the underwater bathymetry. For this analysis it was necessary to choose a depth contour and in this case a depth of $d_{c}=15 \mathrm{~m}$ was chosen for predicted wave run-up. The depth was selected for three reasons. Firstly the 'annual cutoff depth $d_{c}$ ' as defined by Bruun (1954), along this coastline is between 10 and 18m (Theron, 1994; Mather, unpublished data). Secondly, the $15 \mathrm{~m}$ depth contour is typically available on regional Admiralty charts (South African Navy, 2007). Thirdly this is approximately the depth where regional maximum wave heights of around 8 to $10 \mathrm{~m}$ would "feel the bottom". Naval charts were obtained to provide the bathymetry. A further check on the accuracy of the model was undertaken in KZN by using aerial photography taken after the KwaZulu-Natal event and comparing the predicted wave run up position against the observed debris line form aerial photography. The earlier wave run up research work by Holman (1986), Nielsen and Hanslow (1991), Douglass (1992) and Stockdon et al. (2006) was used to compare the performance of the newly developed wave run up model. 
RESULTS AND DISCUSSION

The data shows that wave run up is highest for steep beach slopes which is agreement with the theory as can be seen in Figure 2 below.

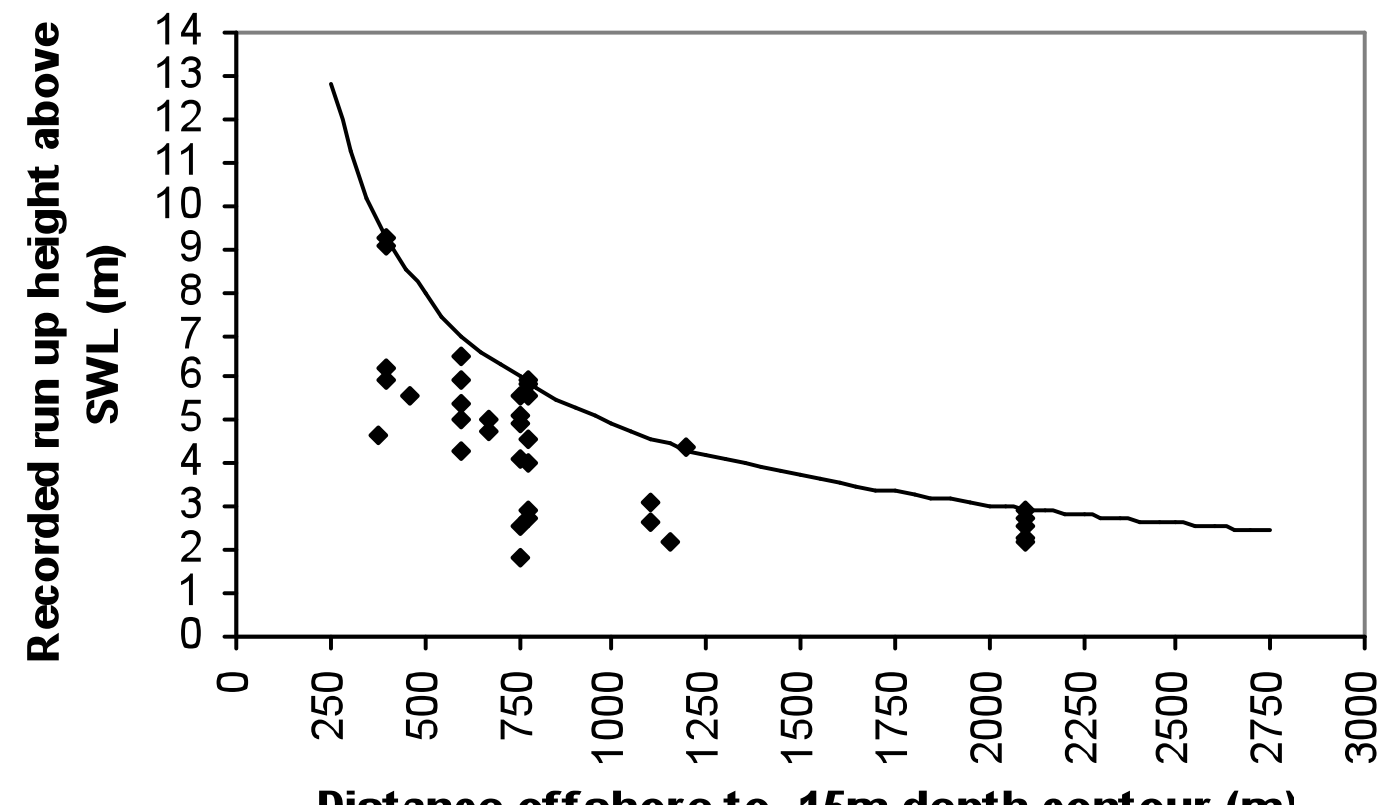

Figure 2: Recorded wave run up against SWL for the March 2007 event in KwaZulu-Natal.

The use of the Holman (1986), Nielsen and Hanslow (1991), Douglass (1992) and Stockdon et al. (2006) wave run up models gave a considerable scatter of the predicted wave run up verse actual measured wave run up at these locations in the March 2007 event as shown in Figure 3a, b, c and d. 

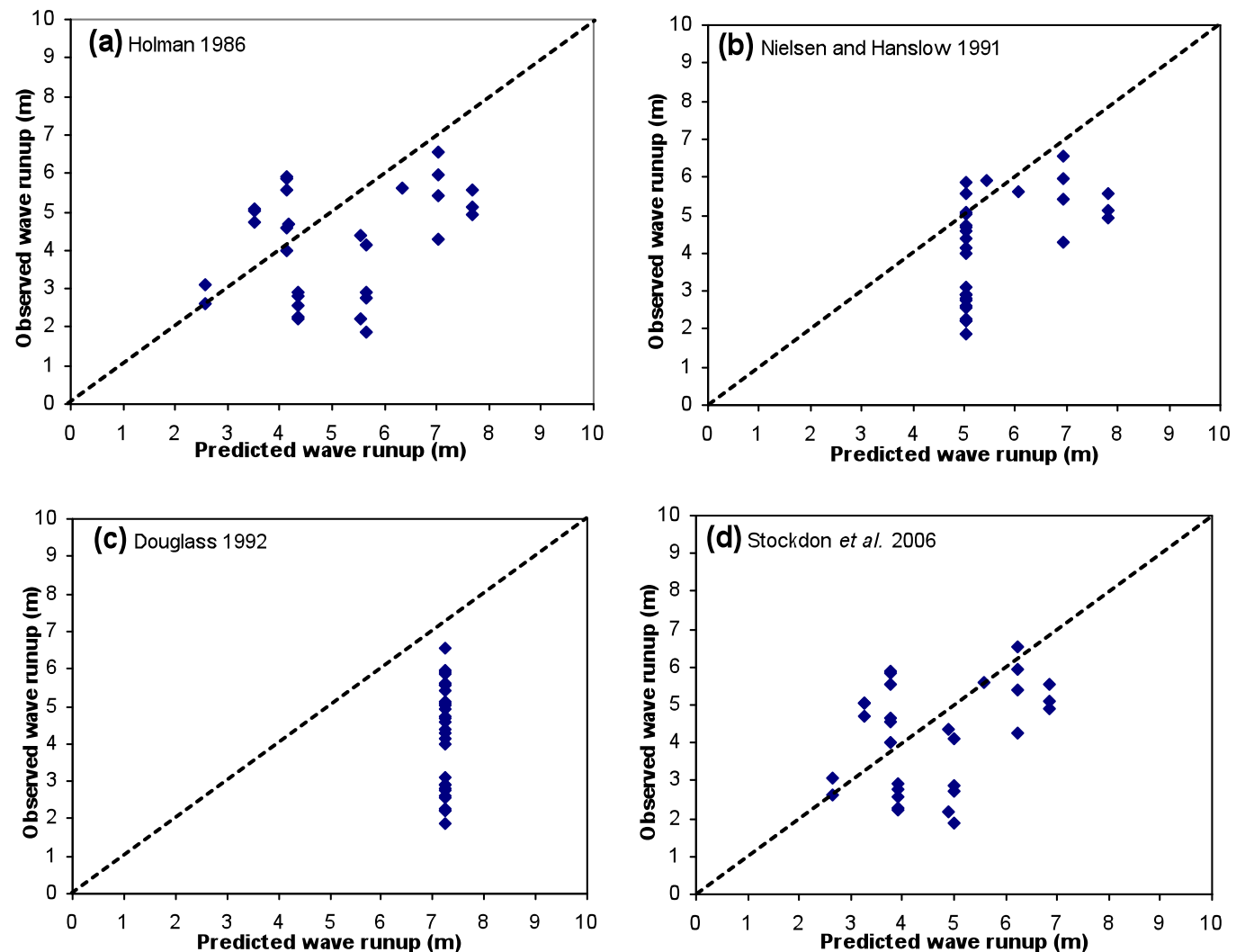

Figure 3: Observed against predicted wave run-up for the KZN March 2007 storm (a) Holman 1986, (b) Nielsen and Hanslow 1991, (c) Douglass 1992 and (d) Stockdon et al. 2006.

Consideration was then given to a new predictive wave run up model. Observations show that not only does wave run up height vary with beach slope but it also varies with the bathymetric profile. This is not unexpected as it has been shown that wave run up is proportional to beach slope which in turn is related to sand grain size and beach profile shape. In order to simplify the representation of the bathymetric profile a single measurement is proposed. Assuming that bathymetric profiles are of a particular shape based on the natural wave climate and physical characteristics of the beach, each profile can be described by a single point on the profile. The annual cut off depth determined from analysing 30 years of annual bathymetric profiles along the KwaZulu-Natal coast is suggested as a suitable reference point. This depth was determined as the $-15 \mathrm{~m}$ contour. The measured maximum wave run up $R_{\max }$ was then plotted against the distance offshore from the SWL to the $-15 \mathrm{~m}$ bathymetric contour along the coastline as previously shown in Figure 2. An upper bound curve was derived from these data as

$$
R_{\max }=C H_{m 0} S^{2 / 3}
$$

where $\mathrm{C}$ is a dimensionless coefficient, $H_{\mathrm{m} 0}$ is the deep water significant wave height, and $\mathrm{S}=\Delta \mathrm{H} / \Delta \mathrm{X}$ (with $\Delta \mathrm{H}=15 \mathrm{~m}$ and $\Delta \mathrm{X}=$ distance $(\mathrm{m})$ to the $-15 \mathrm{~m}$ contour) is a representative near shore slope. The data for the open coastline of KwaZulu-Natal gives a curve fitting upper bound where the value $\mathrm{C}=10$. This equation was then verified against 989 observed locations of maximum wave run up along the KwaZulu-Natal coastline identified from aerial photography taken shortly after the storm. Using a high resolution digital terrain model the wave run up predicted by equation (1) was compared with the position of the beach scarp observable on the aerial photographs. The horizontal error distance was calculated using all 989 locations and is shown in Figure 4 below. 


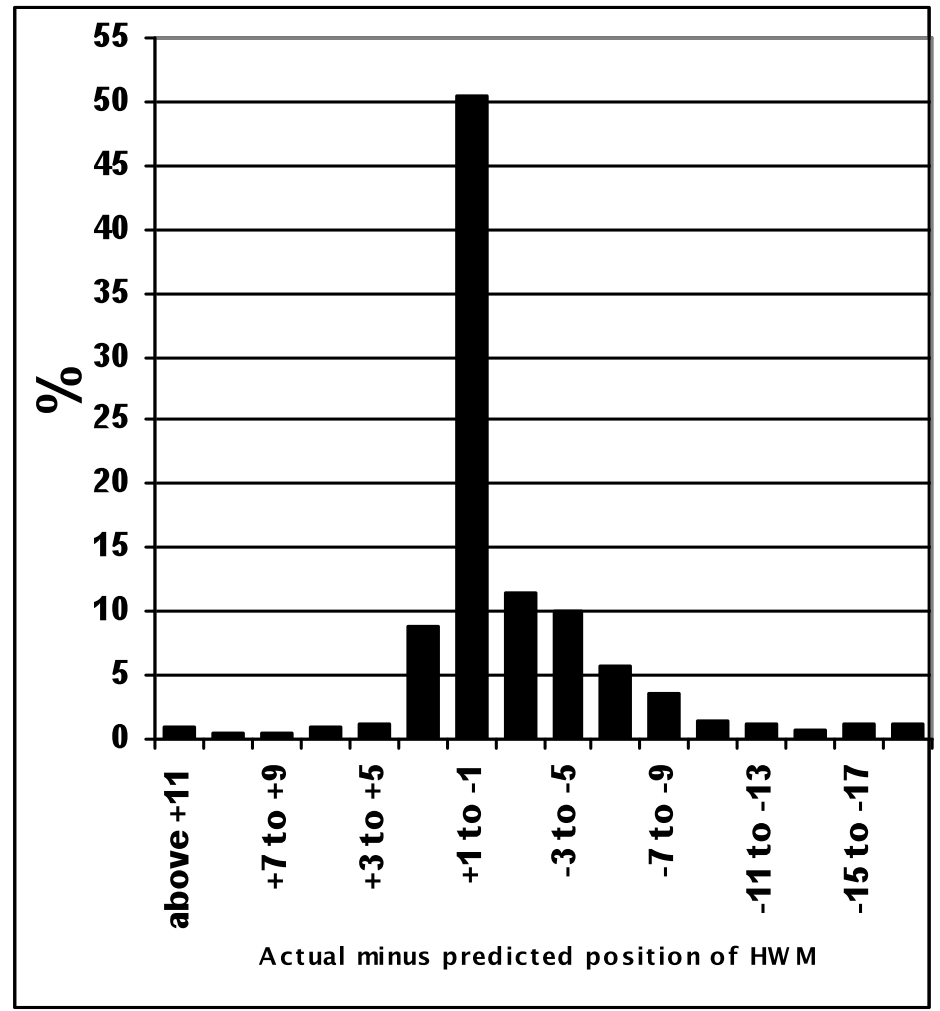

Figure 4: Difference between the actual horizontal wave run up position verse predicted position

The results show that $52 \%$ of the predicted maximum wave run up positions fall within one metre of the measured wave run up positions. The equation gives a slight average over prediction of $1.6 \mathrm{~m}$ in the horizontal plane.

The model developed for the KwaZulu-Natal event was also tested for the Cape event (see Figure 5) and the results support equation (1) with $\mathrm{C}=10$ for open coastline, but required an adjustment of the coefficient to $\mathrm{C}=9$ for large embayments and $\mathrm{C}=6$ for small embayments. When the model was applied to both the KZN and Cape wave run up events good agreement between predicted and observed wave run up was found as shown in Figure 6.

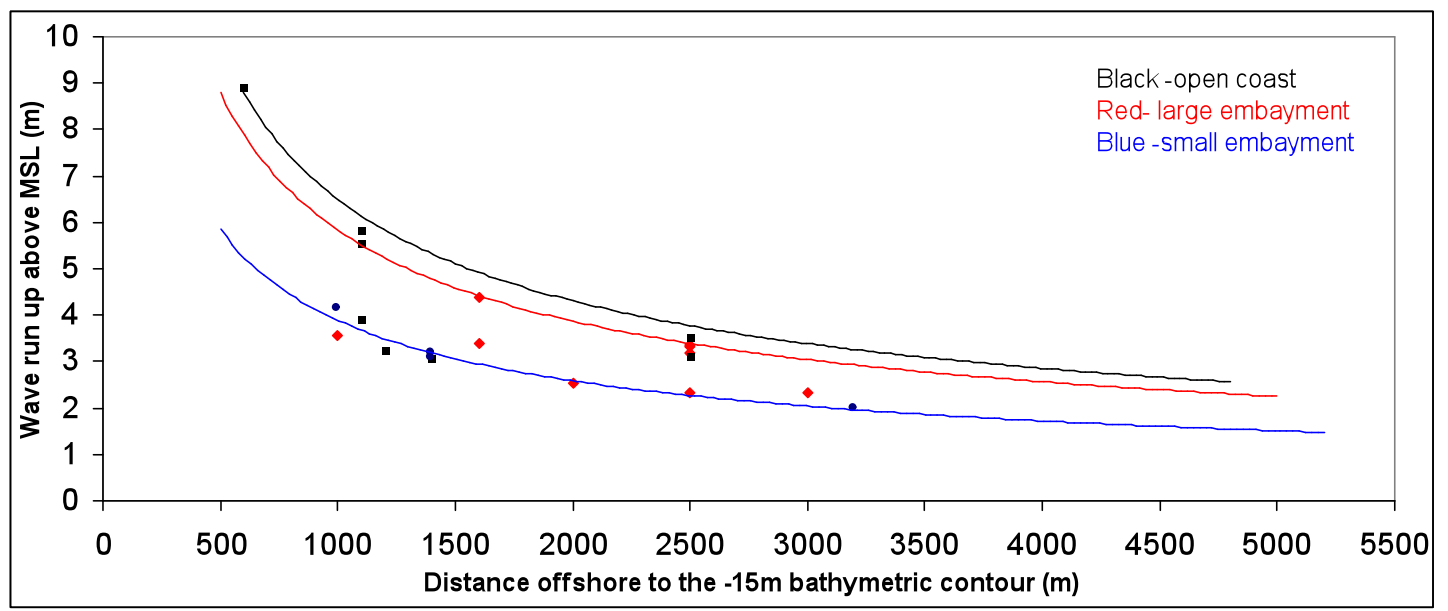

Figure 5: Predicted verse actual wave run up for the September 2008 storm event in the Cape. 


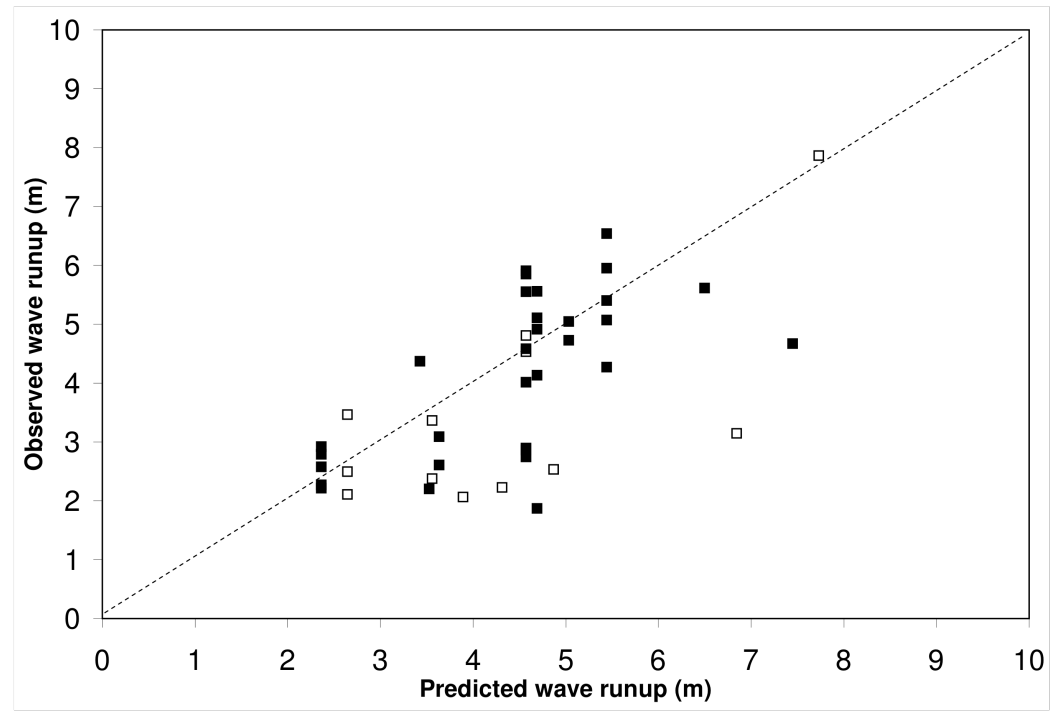

Figure 6: Observed verse predicted wave run up using new model for KZN and Cape storm events (KZN solid squares and Cape event hollow squares).

\section{CONCLUSION}

In this paper we have approached the problem from a new and different perspective. Using the established relationships between the beach variables, expected maximum wave run-up, defined for a particular time span of storm conditions, has in this case been expressed as a function of the distance offshore to a chosen depth contour. The authors have shown that the proposed model slightly overpredicts (average of $1.6 \mathrm{~m}$ horizontal distance inland) and this may well be a function of the choice of the beach scarp slope that may not have reached its maximum inland position. This scarp slope may well have moved further inland with a longer storm duration. Under the circumstances, this small difference is considered negligible and this approach provides a good indication of wave run up position on natural beaches. This simple wave run up formula has been applied to wave run up during wave events and found to be suitable for predicting the wave run up heights for natural beaches. This provides a quick and easy to apply method for estimating wave run up enabling the hazard zone to be determined for planning purposes.

\section{REFERENCES}

Bruun, P., 1954. Coastal erosion and development of beach profiles, U.S. Army Beach Erosion Board Technical Memorandum 44, U.S. Army Corps of Engineers, Waterways Experiment Station, Vicksburg, Mississippi, USA.

Douglass, S.L. 1992. Estimating extreme values of run-up on beaches, Journal of Waterway, Port, Coastal and Ocean Engineering, 118(2), ASCE.

Holman, R.A., 1986. Extreme value statistics for wave run-up on a natural beach, Coastal Engineering, 9, 527-544.

Nielsen, P. 2010. Pers Comm. Dept. of Civil Engineering, University of Queensland, Australia.

Nielsen, P. and Hanslow, D.J., 1991. Wave run-up distributions on natural beaches, Journal of Coastal Research, 7(4), 1139-1152.

South African Navy, 2007. 2007 South African Tide Tables, South African Navy, Tokai, South Africa Stockdon, H.F., Holman, R.D., Howd, P.A. and Sallenger, A.H., 2006. Empirical parameterization of setup, swash and run-up, Coastal Engineering, 53 (7), 573-588.

Theron, A.K., 1994. Sea level rise, impacts and the use of Bruun's erosion Rule, Journal of the South African Institute of Civil Engineers, 36(3), 6-10. 